\title{
Accelerating forward genetics for cell wall deconstruction
}

\author{
Danielle Vidaurre ${ }^{1}$ and Dario Bonetta ${ }^{2}$ * \\ ${ }^{1}$ Department of Cell and Systems Biology, University of Toronto, Toronto, ON, Canada \\ ${ }^{2}$ Faculty of Science, University of Ontario Institute of Technology, Oshawa, ON, Canada
}

Edited by:

Seth DeBolt, University of Kentucky,

USA

\section{Reviewed by:}

Samuel P. Hazen, University of

Massachusetts, USA

William Underwood, University of

California at Berkeley, USA

\section{*Correspondence:}

Dario Bonetta, Faculty of Science,

University of Ontario Institute of

Technology, 2000 Simcoe Street

North, Oshawa, ON, Canada L1H 7K4.

e-mail:dario.bonetta@uoit.ca
The elucidation of the genes involved in cell wall synthesis and assembly remains one of the biggest challenges of cell wall biology. Although traditional genetic approaches, using simple yet elegant screens, have identified components of the cell wall, many unknowns remain. Exhausting the genetic toolbox by performing sensitized screens, adopting chemical genetics or combining these with improved cell wall imaging, hold the promise of new gene discovery and function. With the recent introduction of next-generation sequencing technologies, it is now possible to quickly and efficiently map and clone genes of interest in record time. The combination of a classical genetics approach and cutting edge technology will propel cell wall biology in plants forward into the future.

Keywords: cell wall, forward genetics, genetic screen, next-generation mapping, Arabidopsis

\section{CLASSICAL FORWARD GENETICS}

Technological advances have changed how biological systems are studied by making it easier to collect vast amounts of data, and have even created scenarios where entire genomes can be sequenced in relatively short time frames. Progress in understanding complex networks, and the functionality of their components has, however, been far slower. For example, an estimated 15\% of plant genes in Arabidopsis thaliana might be involved in the biosynthesis and metabolism of the plant cell wall and only a small subset have been characterized (Carpita et al., 2001; Liepman et al., 2010). The task of identifying the relevant genes in cell wall assembly and maintenance is a daunting one. However, deep sequencing platforms like Illumina's Genome Analyzer or ABI's SOLiD have changed the genetic horizon once again and hold the promise of narrowing the knowledge gap at a quicker pace. In model systems like Arabidopsis, this technology shrinks the time frame of positionally cloning a gene from months to days. For emerging models, it means that gene mapping is within reach; creating opportunities for expanding the use of genetics in these systems. The scope of this review is to look back at the successful application of forward genetics in Arabidopsis cell wall biology and suggest that, in light of the new sequencing platforms, it is worthwhile to intensify efforts using forward genetic approaches to understand cell wall biology.

Forward genetics is extremely powerful because of its exploratory nature; with no bias or a priori knowledge required about the pathways involved in a process. Forward genetics also has the advantage that it often utilizes mutagens that induce a wide spectrum of mutations, which can be used to generate an allelic series. For example, ethyl methanesulfonate (EMS) mutagenesis causes point mutations that can lead to amorphic, hypomorphic, hypermorphic, neomorphic, as well as conditional mutations; potentially obviating the pitfall of genetic redundancy or lethality. This variety of mutations far exceeds what is possible with biological mutagens, like T-DNA or transposons, which typically lead to amorphic alleles. Point mutations can also be informative with respect to the domain structure of the affected gene product. However, some of the limitations of forward genetics are that the screening process can be slow and laborious, and identifying the mutation using traditional positional cloning techniques can be tedious and time-consuming.

Despite the drawbacks, many cell wall-related genes have been identified using forward genetic screens using simple phenotypes such as hypocotyl length or root swelling. Although many morphological screens had a developmental rather than cell wallspecific scope, they have provided unequivocal evidence of the involvement of a number of genes in cell wall synthesis (see Hématy and Höfte, 2007 for review). In retrospect it might not be surprising that the genes identified through these screens, which focused on reduced cell elongation or anisotropy, are enriched in components related to cellulose synthesis. Indeed, one of the first genes identified from these screens was a cellulose synthase (CESA; Arioli et al., 1998). However, proteins not predicted to be involved in cellulose biosynthesis (Nicol et al., 1998; Zhong et al., 2000; Schindelman et al., 2001; Pagant et al., 2002) were also identified using this approach. While morphological screens might seem too generalized, they are relatively straightforward and can be scaled to saturation until an allelic series is generated. Since the screens can be done on Petri plates, the only real equipment that might be needed is a dissecting microscope, making them accessible to most labs. Furthermore, because they cast a large net, unintended targets might be identified that would be excluded by screens that are more focused. Although their precise function is still not known, it is unlikely that many of the non-CESA genes mentioned above would have been isolated if not for these screens. When dealing with complex, developmentally regulated structures like the cell wall it is foreseeable that we will continue to identify many more unexpected players. It seems, that in the case of this genetic fishing expedition, the by catch is a good thing.

Important players of cellulose biosynthesis have also been identified by more focused mutant screens. These have depended on 
the use of specific inhibitors of cellulose biosynthesis or on ultrastructural changes of the wall. For example, resistance to the cellulose biosynthesis inhibitor (CBI), isoxaben, identified CESAs (CESA3 and 6), which are part of the cellulose synthase complex responsible for deposition of cellulose in primary walls (Scheible et al., 2001; Desprez et al., 2002). The advantage of using chemicals such as isoxaben is that a change in response to the chemical is clear-cut, and if resistance mutants are desired, then it is a simple matter to select for them on plates. An alternative screening method, which identified CESA genes involved in secondary wallcellulose synthesis, was accomplished by screening sectioned stems for a collapsed xylem phenotype (Turner and Somerville, 1997; Taylor et al., 1999, 2000). Apart from CESAs this screen has also identified genes involved in lignin synthesis (Jones et al., 2001); again highlighting the power of genetic screens to identify a variety of cell wall constituents. Although screens like this one are more laborious than those based on inhibitor response, they obviously identify a different spectrum of genes that available inhibitors do not currently target.

A further refinement of cell wall-directed screening was achieved by Reiter et al. (1997) who performed a screen characterizing the monosaccharide composition of the cell wall mutants by gas-chromatography. This classic and laborious screen was performed on 5,200 mutagenized Arabidopsis plants resulting in 11 mur complementation groups, of which 5 have been cloned. mur mutants with deficiencies in a single sugar were due to mutations in a dehydratase (Bonin et al., 1997), an epimerase (Burget et al., 2003), and transferases (Vanzin et al., 2002; Madson et al., 2003), whereas mur mutants deficient in numerous monosaccharides are due to mutations in CESA7 (Bosca et al., 2006) and SAC9, a phosphoinositide phosphatase (Austin et al., 2011). A similar screening protocol was utilized by Gardner et al. (2002) to identify variation in stem cell wall composition following hydrolysis with Driselase or trifluoroacetic acid. Brute-force screens like these have also been used to identify lignin mutants, where phenylpropanoiddeficient mutants were identified using thin-layer chromatography (Chapple et al., 1992). Additional brute-force approaches might be implemented by taking advantage of the analytical techniques used to determine the cell wall composition like oligosaccharide mass profiling method (Lerouxel et al., 2002; Obel et al., 2009), comprehensive microarray polymer profiling (Moller et al., 2007) and Fourier transform infrared microspectroscopy (Mouille et al., 2003). Although more time consuming, the power of these screens is that they have the potential to identify a very small subset of genes, which are directly related to cell wall synthesis or structure.

\section{IDENTIFYING GENE INTERACTIONS}

Once a mutant of interest has been identified from a forward genetic screen, secondary screening using this mutant background allows further dissection of the affected pathway. Due to the large number of gene families in Arabidopsis, many single gene mutations do not result in an observable phenotype (Cutler and McCourt, 2005). When screens are performed on a sensitized background, however, genes with overlapping functions can be unmasked. So, enhancer mutations might uncover a partially redundant pathway, while suppressor mutations may uncover interacting proteins or alternate pathways that become activated by the second-site suppressor. Overall, modifier screens are a powerful and, in plants, mostly underutilized method for the discovery of gene interaction.

There are very few examples of modifier screens in plant cell wall research (Diet et al., 2006; Hématy et al., 2007). One notable example, which demonstrates the utility of such a screen, was the identification of theseus1 (the1; Hématy et al., 2007), a semidominant suppressor of the cellulose-deficient mutant procuste1-1 (prc1-1); a mutant affected in CESA6 (Fagard et al., 2000). Mutants defective in prcl display cellulose deficiency and develop short hypocotyls when grown in the dark, whereas, the 1; prc1-1 double mutants suppress the short hypocotyl phenotype but not the cellulose deficiency. THE1 belongs to the Catharanthus roseus protein-kinase-1-like family that plays a role in monitoring the integrity of the cell wall (Hématy et al., 2007). Although much is known about maintaining cell wall integrity in yeast, in which stress-sensing proteins act to redistribute the cell wall machinery to repair cell wall damage (Levin, 2011), the identification of THE1 is the first example of a potential cell wall integrity sensor in plants. The next step is to characterize the signaling pathway in which THE1 functions; the identification of the upstream activators or ligand(s) of THE1 and the downstream genes in the control of cell elongation and the defense against pathogens. In this respect, recent studies have begun to identify the role of the plant hormones, such as brassinosteroids, in the transcriptional regulation of THE1 and other related receptor-like kinases (Guo et al., 2009).

\section{CHEMICAL GENETICS TO PROBE THE CELL WALL}

The central principle of chemical genetics is the use of small, chemically diverse molecules to specifically target cellular gene products. In a manner analogous to mutation, the molecules are used to probe biological pathways by the activity of a target protein. Combinatorial chemistry has made it possible to generate large synthetic compound libraries, which can be used to distinguish multiple protein targets in a single pathway and so can be very specific. One major advantage of chemical genetics over classical genetics is that application of the chemicals is both tuneable and reversible. Chemicals can be targeted with spatiotemporal precision against a selected spectrum of proteins (in contrast to targeting one gene at a time), applied in defined dosage to distinct cells, organs or developmental stages. Since small molecules can be used to inactivate a family of proteins in a single step, they are ideal for functional characterization of genes with redundant functions, or can result in the selection of conditional mutants addressing loss-of-function lethality. When used in combination with classical genetics, a high-throughput screen might identify mutants that display an altered phenotype such as hypersensitivity or resistance to the chemical. Mutations conferring resistance/hypersensitivity can either affect the target of the chemical or upstream and downstream components of its target of the affected biological pathway (Raikhel and Pirrung, 2005; Norambuena et al., 2009).

Successful chemical genetic screens have been used in identifying components of the auxin signaling pathway (Armstrong et al., 2004), endomembrane system and gravitropism components (Surpin et al., 2005; Rosado et al., 2011), cytoskeleton-cellulose 
synthesis interaction in plants (DeBolt et al., 2007; Yoneda et al., 2007, 2010), and abscisic acid (ABA) receptors (Park et al., 2009). The use of chemical genetic screens has not been saturated in cell wall research as it has in other organisms. However, they offer a promising tool that, when used in combination with classical genetics, can be extremely powerful. An example of this is the use of chemical and classical genetics to isolate ABA receptors (Park et al., 2009). Here the authors were able to identify an elusive receptor by utilizing a molecule that occupied different chemical space from the endogenous hormone. Similar scenarios might be imagined for cell wall structural or regulatory proteins. An interesting twist on the principle of chemical genetics has been to use an enzyme rather than a small molecule to direct a forward genetic screen (Gille etal., 2009). In this approach the authors used a hydrolase to identify mutants with altered response to the enzyme. The success of this screen highlights how cell wall perturbing molecules, whether small molecules, toxins or enzymes, can be used to identify novel cell wall-related genes by straightforward screening methods.

\section{GENE DISCOVERY USING NEXT-GENERATION MAPPING}

The whole genome sequence of model systems like Arabidopsis greatly shortened the time required to clone a gene from years to months, not only because it provided a reference genome but also because it eliminated the need to identify polymorphisms (Lukowitz etal., 2000). Despite this advance, mapping genes remained a protracted, labor-intensive and challenging endeavor. However, next generation sequencing technologies have shortened the time required to go from phenotype to gene down to days rather than months. Approaches to gene mapping using whole genome sequencing have been widely used to map causative mutations in various model organisms such as yeast (Smith et al., 2008; Irvine etal., 2009), bacteria (Srivatsan etal., 2008), C. elegans (Sarin et al., 2008; Zuryn et al., 2010), Drosophila (Blumenstiel etal., 2009), and Arabidopsis (Schneeberger et al., 2009; Hong etal., 2010; Austin etal., 2011). Many more examples of this approach will certainly emerge and with each successive study it is expected that the tools for mapping using whole genome sequencing (or next-generation mapping, NGM) will continue to improve. The cost of NGM is also expected to decrease; even though it is already very cost effective considering the cost of reagents and personnel hours that are required for traditional mapping projects.

There are two basic approaches that have been used to positionally clone genes by NGM. The first, more straightforward approach is to sequence the mutated genome and compare it to a reference, unmutagenized genome (Sarin et al., 2008). Because chemical mutagens like EMS tend to induce many mutations in the genome (Kurowska etal., 2011) the challenge is to identify the causative mutation out of this high level of sequence variation. One strategy to mitigate this problem is to roughly map the mutation before sequencing, so that once the mutant sequence is available then only a region of the genome is scrutinized. This scenario can be further improved if multiple alleles at the same locus are available so that they can be sequenced in parallel along with the reference. Since multiple alleles are generally desirable anyway, this aspect of cloning does not increase the work required to undertake NGM. The approach that has been used so far in Arabidopsis (Schneeberger et al., 2009; Hong et al., 2010), but also in C. elegans (Doitsidou et al., 2010), is based on bulked segregant analysis (Michelmore et al., 1991), whereby a mutant is crossed to a divergent wild-type to generate F2 progeny, which are then selected for their mutant phenotype and whose DNA is pooled and analyzed by whole genome sequencing. Refinement of this approach has shown that it is possible to accomplish this with no prior mapping information and using only a small $\mathrm{F} 2$ population to map candidate causative mutations (Austin et al., 2011). An important upshot of this work has been the development of a web-based, bioinformatic tool that is freely available to the scientific community, which can identify causative mutations in Arabidopsis (and other model organisms) once data is uploaded onto the web interface (Austin et al., 2011). This means that non-experts have the ability to take advantage of NGM and can easily perform their analysis in a matter of a few hours.

The impact of NGM in model genetic systems will be widespread. The speed of NGM means that multiple mutant pools can be handled simultaneously; making it easier to approach mutational saturation of a process and determine the relevant pathways involved in that process. Furthermore, researchers will now be free to spend their time designing new and inventive screens and understanding gene interaction, rather than in the doldrums of mapping. As an added bonus, even mutants obtained from time-consuming screens, with subtle or unwieldy phenotypes will be more easily accessed by NGM. This will include mutations that are very sensitive to genetic background, which are especially useful in bypassing genetic redundancy and might have been difficult to map previously. In addition, second-site modifiers or, taking it one step further, polygenic traits, will be more tractable through NGM, since candidates can be identified directly. Finally, one of the most exciting prospects of NGM is that mapping mutations in emerging model systems is also very close at hand. This means that the diversity of cell walls in different species (Popper et al., 2011) might be explored more deeply than it has been in the past.

In the context of the cell wall, there is still a lot of opportunity to expand the mutant collection. For example, it will be worthwhile to revisit many of the same screens that have been successful in the past, since many were not done to saturation. However, because of the nature of the wall simple screens based solely on morphology or growth characteristics will be limited. One lesson from previous screens that is clear is that these will continue to uncover components of the cellulose biosynthetic machinery. Therefore, cell walldirected screens will ideally incorporate some additional tools. For example, morphology based screens could be extended by utilizing any number of the available cell wall probes like monoclonal antibodies, fluorescent tags, carbohydrate binding modules, or specific dyes. These probes could be used on tissues or specific cell types depending on the motivation behind the screen. Combining chemical genetics with classical genetics also has the potential to be very productive. Efforts could be devoted, for example, toward identifying inhibitors that target specific cell wall constituents. Since inhibitors can tackle functional redundancy, it would provide an alternative approach to reverse genetics in identifying relevant enzyme and regulatory networks for cell wall synthesis. 
Once identified, it would be possible to use these inhibitors to then isolate their targets through resistance phenotypes. Whatever the approach, the current mutant collection has an underrepresentation of regulators for cell wall synthesis, assembly or integrity, and future efforts could strive to focus on identifying these. The benefit of having at least a few regulators in hand is that it will provide a framework for understanding cell wall dynamics.

\section{REFERENCES}

Arioli, T., Peng, L., Betzner, A. S., Burn, J., Wittke, W., Herth, W., Camilleri, C., Höfte, H., Plazinski, J., Birch, R., Cork, A., Glover, J., Redmond, J., and Williamson, R. E. (1998). Molecular analysis of cellulose biosynthesis in Arabidopsis. Science 279, 717-720.

Armstrong, J. I., Yuan, S., Dale, J. M., Tanner, V. N., and Theologis, A. (2004). Identification of inhibitors of auxin transcriptional activation by means of chemical genetics in Arabidopsis. Proc. Natl. Acad. Sci. U.S.A. 101, 14978-14983.

Austin, R. S., Vidaurre, D., Stamatiou, G., Breit, R., Provart, N. J., Bonetta, D., Zhang, J., Fung, P., Gong, Y., Wang, P. W., McCourt, P., and Guttman, D. S. (2011). Nextgeneration mapping of Arabidopsis genes. Plant J. 67, 715-725.

Blumenstiel, J. P., Noll, A. C., Griffiths, J. A., Perera, A. G., Walton, K. N., Gilliland, W. D., Hawley, R. S., and Staehling-Hampton, K. (2009). Identification of EMS-induced mutations in Drosophila melanogaster by whole-genome sequencing. Genetics 182, 25-32.

Bonin, C. P., Potter, I., Vanzin, G. F., and Reiter, W. D. (1997). The MUR1 gene of Arabidopsis thaliana encodes an isoform of GDP-D-mannose-4,6dehydratase, catalyzing the first step in the de novo synthesis of GDP-Lfucose. Proc. Natl. Acad. Sci. U.S.A. 94, 2085-2090.

Bosca, S., Barton, C. J., Taylor, N. G., Ryden, P., Neumetzler, L., Pauly, M., Roberts, K., and Seifert, G. J. (2006). Interactions between MUR10/CesA7-dependent secondary cellulose biosynthesis and primary cell wall structure. Plant Physiol. 142, 1353-1363.

Burget, E. G., Verma, R., Mølhøj, M., and Reiter, W. D. (2003). The biosynthesis of L-arabinose in plants: molecular cloning and characterization of a Golgi-localized UDP-D-xylose 4epimerase encoded by the MUR4 gene of Arabidopsis. Plant Cell 15, 523-531.

Carpita, N. C., Defernez, M., Findlay, K., Wells, B., Shoue, D. A., Catchpole, G., Wilson, R. H., and McCann, M. C. (2001). Cell wall architecture of the elongating maize coleoptile. Plant Physiol. 127, 551-565.

Chapple, C. C., Vogt, T., Ellis, B. E., and Somerville, C. R. (1992). An Arabidopsis mutant defective in the general phenylpropanoid pathway. Plant Cell 4, 1413-1424.

Cutler, S., and McCourt, P. (2005). Dude, where's my phenotype? Dealing with redundancy in signaling networks. Plant Physiol. 138, 558-559.

DeBolt, S., Gutierrez, R., Ehrhardt, D. W., Melo, C. V., Ross, L., Cutler, S. R., Somerville, C., and Bonetta, D. (2007). Morlin, an inhibitor of cortical microtubule dynamics and cellulose synthase movement. Proc. Natl. Acad. Sci. U.S.A. 104, 5854-5859.

Desprez, T., Vernhettes, S., Fagard, M., Refrégier, G., Desnos, T., Aletti, E., Py, N., Pelletier, S., and Höfte, H. (2002). Resistance against herbicide isoxaben and cellulose deficiency caused by distinct mutations in same cellulose synthase isoform CESA6. Plant Physiol. 128, 482-490.

Diet, A., Link, B., Seifert, G. J., Schellenberg, B., Wagner, U., Pauly, M., Reiter, W. D., and Ringli, C. (2006). The Arabidopsis root hair cell wall formation mutant lrx1 is suppressed by mutations in the RHM1 gene encoding a UDP-L-rhamnose synthase. Plant Cell 18, 1630-1641.

Doitsidou, M., Poole, R. J., Sarin, S., Bigelow, H., and Hobert, O. (2010). C. elegans mutant identification with a one-step whole-genomesequencing and SNP mapping strategy. PLoS ONE 5, e15435. doi: 10.1371/journal.pone.0015435

Fagard, M., Desnos, T., Desprez, T., Goubet, F., Refregier, G., Mouille, G., McCann, M., Rayon, C., Vernhettes, S., and Höfte, H. (2000). PROCUSTE1 encodes a cellulose synthase required for normal cell elongation specifically in roots and dark-grown hypocotyls of Arabidopsis. Plant Cell 12, 2409-2424.

Gardner, S. L., Burrell, M. M., and Fry, S. C. (2002). Screening of Arabidopsis thaliana stems for variation in cell wall polysaccharides. Phytochemistry 60, 241-254.

Gille, S., Hänsel, U., Ziemann, M., and Pauly, M. (2009). Identification of plant cell wall mutants by means of

It is an exciting time for cell wall geneticists with new emerging fields and tools for research exploration and discovery. Retooling what has been proven so successful in the past, the use of classical genetics for basic research, and integrating technology in innovative and novel ways, will be critical in moving forward at an unprecedented pace in uncovering the components involved in the cell wall.

a forward chemical genetic approach using hydrolases. Proc. Natl. Acad. Sci. U.S.A. 106, 14699-14704.

Guo, H., Li, L., Ye, H., Yu, X., Algreen, A., and Yin, Y. (2009). Three related receptor-like kinases are required for optimal cell elongation in Arabidopsis thaliana. Proc. Natl. Acad. Sci. U.S.A. 106, 7648-7653.

Hématy, K., and Höfte, H. (2007). "Cellulose and cell elongation," in The Expanding Cell, eds J. P. Verbelen and K. Vissenberg (Berlin: Springer Verlag), 33-56.

Hématy, K., Sado, P. E., Van Tuinen, A., Rochange, S., Desnos, T., Balzergue, S., Pelletier, S., Renou, J. P., and Höfte, H. (2007). A receptorlike kinase mediates the response of Arabidopsis cells to the inhibition of cellulose synthesis. Curr. Biol. 17, 922-931.

Hong, S., Song, H.-R., Lutz, K., Kerstetter, R. A., Michael, T. P., and McClung, C. R. (2010). Type II protein arginine methyltransferase 5 (PRMT5) is required for circadian period determination in Arabidopsis thaliana. Proc. Natl. Acad. Sci. U.S.A. 107, 21211-21216.

Irvine, D. V., Goto, D. B., Vaughn, M. W., Nakaseko, Y., McCombie, W. R., Yanagida, M., and Martienssen, R. (2009). Mapping epigenetic mutations in fission yeast using wholegenome next-generation sequencing. Genome Res. 19, 1077-1083.

Jones, L., Ennos, A. R., and Turner, S. R. (2001). Cloning and characterization of irregular xylem4 (irx4): a severely lignin-deficient mutant of Arabidopsis. Plant J. 26, 205-216.

Kurowska, M., Daszkowska-Golec, A., Gruszka, D., Marzec, M., Szurman, M., Szarejko, I., and Maluszynski, M. (2011). TILLING: a shortcut in functional genomics. J. Appl. Genet. 52, 371-390.

Lerouxel, O., Choo, T. S., Séveno, M., Usadel, B., Faye, L., Lerouge, P., and Pauly, M. (2002). Rapid structural phenotyping of plant cell wall mutants by enzymatic oligosaccharide fingerprinting. Plant Physiol. 130, 1754-1763.

Levin, D. E. (2011). Regulation of cell wall biogenesis in Saccharomyces cerevisiae: the cell wall integrity signaling pathway. Genetics 189, 1145-1175.
Liepman, A. H., Wightman, R., Geshi, N., Turner, S. R., and Scheller, H. V. (2010). Arabidopsis - a powerful model system for plant cell wall research. Plant J. 61, 1107-1121.

Lukowitz, W., Gillmor, C. S., and Scheible, W. R. (2000). Positional cloning in Arabidopsis. Why it feels good to have a genome initiative working for you. Plant Physiol. 123, 795-805.

Madson, M., Dunand, C., Li, X., Verma, R., Vanzin, G. F., Caplan, J., Shoue, D. A., Carpita, N. C., and Reiter, W. D. (2003). The MUR3 gene of Arabidopsis encodes a xyloglucan galactosyltransferase that is evolutionarily related to animal exostosins. Plant Cell 15, 1662-1670.

Michelmore, R. W., Paran, I., and Kesseli, R. V. (1991). Identification of markers linked to disease-resistance genes by bulked segregant analysis: a rapid method to detect markers in specific genomic regions by using segregating populations. Proc. Natl. Acad. Sci. U.S.A. 88, 9828-9832.

Moller, I., Sørensen, I., Bernal, A. J., Blaukopf, C., Lee, K., Øbro, J., Pettolino, F., Roberts, A., Mikkelsen, J. D., Knox, J. P., Bacic, A., and Willats, W. G. (2007). High-throughput mapping of cell-wall polymers within and between plants using novel microarrays. Plant J. 50, 1118-1128.

Mouille, G., Robin, S., Lecomte, M. Pagant, S., and Höfte, H. (2003). Classification and identification of Arabidopsis cell wall mutants using Fourier-Transform InfraRed (FT-IR) microspectroscopy. Plant J. 35 , 393-404.

Nicol, F., His, I., Jauneau, A., Vernhettes, S., Canut, H., and Höfte, H. (1998). A plasma membrane-bound putative endo-1,4-beta-D-glucanase is required for normal wall assembly and cell elongation in Arabidopsis. EMBO J. 17, 5563-5576.

Norambuena, L., Raikhel, N. V., and Hicks, G. R. (2009). Chemical genomics approaches in plant biology. Methods Mol. Biol. 553, 345-354.

Obel, N., Erben, V., Schwarz, T., Kühnel, S., Fodor, A., and Pauly, M. (2009). Microanalysis of plant cell wall polysaccharides. Mol. Plant 2, 922-932. 
Pagant, S., Bichet, A., Sugimoto, K., Lerouxel, O., Desprez, T., McCann, M., Lerouge, P., Vernhettes, S., and Höfte, H. (2002). KOBITO1 encodes a novel plasma membrane protein necessary for normal synthesis of cellulose during cell expansion in Arabidopsis. Plant Cell 14, 2001-2013.

Park, S. Y., Fung, P., Nishimura, N., Jensen, D. R., Fujii, H., Zhao, Y., Lumba, S., Santiago, J., Rodrigues, A., Chow, T. F., Alfred, S. E., Bonetta, D., Finkelstein, R., Provart, N. J., Desveaux, D., Rodriguez, P. L., McCourt, P., Zhu, J. K., Schroeder, J. I., Volkman, B. F., and Cutler, S. R. (2009). Abscisic acid inhibits type $2 \mathrm{C}$ protein phosphatases via the PYR/PYL family of START proteins. Science 324, 1068-1071.

Popper, Z. A., Michel, G., Hervé, C., Domozych, D. S., Willats, W. G., Tuohy, M. G., Kloareg, B., and Stengel, D. B. (2011). Evolution and diversity of plant cell walls: from algae to flowering plants. Annu. Rev. Plant Biol. 62, 567-590.

Raikhel, N., and Pirrung, M. (2005). Adding precision tools to the plant biologists' toolbox with chemical genomics. Plant Physiol. 138, 563-564.

Reiter, W. D., Chapple, C., and Somerville, C. R. (1997). Mutants of Arabidopsis thaliana with altered cell wall polysaccharide composition. Plant J. 12, 335-345.

Rosado, A., Hicks, G. R., Norambuena, L., Rogachev, I., Meir, S., Pourcel, L., Zouhar, J., Brown, M. Q., Boirsdore, M. P., Puckrin, R. S., Cutler, S. R., Rojo, E., Aharoni, A., and Raikhel, N. V. (2011). Sortin1hypersensitive mutants link vacuolartrafficking defects and flavonoid metabolism in Arabidopsis vegetative tissues. Chem. Biol. 18, 187-197.
Sarin, S., Prabhu, S., O’Meara, M. M., Pe'er, I., and Hobert, O. (2008). Caenorhabditis elegans mutant allele identification by wholegenome sequencing. Nat. Methods 5 , 865-867.

Scheible, W. R., Eshed, R., Richmond, T., Delmer, D., and Somerville, C. (2001). Modifications of cellulose synthase confer resistance to isoxaben and thiazolidinone herbicides in Arabidopsis Ixr1 mutants. Proc. Natl. Acad. Sci. U.S.A. 98, 1007910084.

Schindelman, G., Morikami, A., Jung, J., Baskin, T. I., Carpita, N. C., Derbyshire, P., McCann, M. C., and Benfey, P. N. (2001). COBRA encodes a putative GPI-anchored protein, which is polarly localized and necessary for oriented cell expansion in Arabidopsis. Genes Dev. 15, 1115-1127.

Schneeberger, K., Ossowski, S., Lanz, C., Juul, T., Petersen, A. H., Nielsen, K. L., Jørgensen, J. E., Weigel, D., and Andersen, S. U. (2009). SHOREmap: simultaneous mapping and mutation identification by deep sequencing. Nat. Methods 6, 550-551.

Smith, D. R., Quinlan, A. R., Peckham, H. E., Makowsky, K., Tao, W., Woolf, B., Shen, L., Donahue, W. F., Tusneem, N., Stromberg, M. P., Stewart, D. A., Zhang, L., Ranade, S. S. Warner, J. B., Lee, C. C., Coleman, B. E., Zhang, Z., McLaughlin, S. F., Malek, J. A., Sorenson, J. M., Blanchard, A. P., Chapman, J., Hillman, D., Chen, F., Rokhsar, D. S., McKernan, K. J., Jeffries, T. W., Marth, G. T., and Richardson, P. M. (2008). Rapid whole-genome mutational profiling using next-generation sequencing technologies. Genome Res. 18, 1638-1642.
Srivatsan, A., Han, Y., Peng, J., Tehranchi, A. K., Gibbs, R., Wang, J. D., and Chen, R. (2008). Highprecision, whole-genome sequencing of laboratory strains facilitates genetic studies. PLoS Genet. 4, e1000139. doi: 10.1371/journal.pgen. 1000139

Surpin, M., Rojas-Pierce, M., Carter, C., Hicks, G. R., Vasquez, J., and Raikhel, N. V. (2005). The power of chemical genomics to study the link between endomembrane system components and the gravitropic response. Proc. Natl. Acad. Sci. U.S.A. 102, $4902-$ 4907.

Taylor, N. G., Laurie, S., and Turner, S. R. (2000). Multiple cellulose synthase catalytic subunits are required for cellulose synthesis in Arabidopsis. Plant Cell 12, 2529-2540.

Taylor, N. G., Scheible, W. R., Cutler, S., Somerville, C. R., and Turner, S. R. (1999). The irregular xylem 3 locus of Arabidopsis encodes a cellulose synthase required for secondary cell wall synthesis. Plant Cell 11, 769-780.

Turner, S. R., and Somerville, C. R. (1997). Collapsed xylem phenotype of Arabidopsis identifies mutants deficient in cellulose deposition in the secondary cell wall. Plant Cell 9, 689-701.

Vanzin, G. F., Madson, M., Carpita, N. C., Raikhel, N. V., Keegstra, K., and Reiter, W. D. (2002). The mur2 mutant of Arabidopsis thaliana lacks fucosylated xyloglucan because of a lesion in fucosyltransferase AtFUT1. Proc. Natl. Acad. Sci. U.S.A. 99, 3340-3345.

Yoneda, A., Higaki, T., Kutsuna, N., Kondo, Y., Osada, H., Hasezawa, S., and Matsui, M. (2007). Chemical genetics screening identifies a novel inhibitor of parallel alignment of cortical microtubules and cellulose microfibrils. Plant Cell Physiol. 48, 1393-1403.

Yoneda, A., Ito, T., Higaki, T., Kutsuna, N., Saito, T., Ishimizu, T., Osada, H., Hasezawa, S., Matsui, M., and Demura, T. (2010). Cobtorin target analysis reveals that pectin functions in the deposition of cellulose microfibrils in parallel with cortical microtubules. Plant J. 64, 657-667.

Zhong, R., Ripperger, A., and Ye, Z. H. (2000). Ectopic deposition of lignin in the pith of stems of two Arabidopsis mutants. Plant Physiol. 123, 59-70.

Zuryn, S., Le Gras, S., Jamet, K., and Jarriault, S. (2010). A strategy for direct mapping and identification of mutations by whole-genome sequencing. Genetics 186, 427-430.

Conflict of Interest Statement: The authors declare that the research was conducted in the absence of any commercial or financial relationships that could be construed as a potential conflict of interest.

Received: 14 March 2012; accepted: 17 May 2012; published online: 06 June 2012.

Citation: Vidaurre D and Bonetta D (2012) Accelerating forward genetics for cell wall deconstruction. Front. Plant Sci. 3:119. doi: 10.3389/fpls.2012.00119 This article was submitted to Frontiers in Plant Physiology, a specialty of Frontier in Plant Science.

Copyright () 2012 Vidaurre and Bonetta. This is an open-access article distributed under the terms of the Creative Commons Attribution Non Commercial License, which permits non-commercial use, distribution, and reproduction in other forums, provided the original authors and source are credited. 